\title{
EFFECTS ON ADJACENT SEGMENT AFTER MINIMUM FIVE-YEARS FOLLOWING INSTRUMENTED LUMBAR SPINAL FUSION IN INDIAN POPULATION
}

\section{Yogesh Kishorkant Pithwa* \\ FNB Spine Surgery, Consultant Spine Surgeon, HOSMAT Hospital, Bengaluru, India. *Corresponding Author}

ABSTRACT Adjacent segment degeneration [ASD] after instrumented lumbar spinal fusion has been studied extensively in non-Indian population. Present study attempts to evaluate incidence of and factors predisposing to ASD in the Indian population. This was a retrospective study with the inclusion criteria being: patients who underwent lumbar spinal fusion for spondylolisthesis, trauma, infection or deformity with a minimum five-year follow-up. Exclusion criteria: postoperative iatrogenic surgical-site infections, revision surgeries, postoperative implant failure and pseudarthrosis. Radiographs reviewed immediate postoperatively, and at final follow-up. Global lumbar lordosis from Ll-Sl; and angulation and translation of spinal motion segment immediately adjacent [cranial and caudal] to fused segment were studied. ASD was defined using White and Panjabi's criteria. At final follow-up, VAS for lower back as well as lower limbs was noted separately along with walking distance. Twenty patients [49.4+17.4years] included [six males, fourteen females]. ASD was seen in 13 of 20 [65\%] patients. Age $>50$ years at the time of surgery and global lumbar lordosis $<40^{\circ}$ in the immediate postoperative period were identified as significant risk factors for ASD [ $p=0.02$ and 0.03 , respectively]. However, no significant correlation was noted between development of ASD and extension of fusion to sacrum. Nor was there any correlation between ASD and gender or length of fusion. It was also notable that no significant differences were identified in VAS scores and walking distance between patients with and without ASD. To conclude, among the various factors studied, age $>50 y e a r s$ at the time of surgery and immediate postoperative global lumbar lordosis $<400$ were significantly associated with development of ASD after a minimum follow-up of five years.

KEYWORDS : lumbar, adjacent segment, adjacent segment degeneration, adjacent segment disease

\section{INTRODUCTION}

Degeneration of motion segments immediately adjacent to a fused segment is a phenomenon noted quite commonly'. There has been some debate as to whether these changes represent physiological age-related changes or whether these are secondary to abnormal biomechanics induced by the adjacent fusion ${ }^{1}$. In fact, Pellisé F et al noticed that these kinds of changes occur universally across the lumbar spine segments, including in those that are farther off from the fused areas ${ }^{2}$. Adjacent segment disease has also been noted in patients undergoing non-fusion surgeries, calling into question the incrimination of fusion as a causative agent ${ }^{3}$. However, increased pressure and motion in discs immediately adjacent to fusion have been clearly demonstrated in biomechanical experiments in vitro ${ }^{4}$. A lot of other clinical studies too, echo a similar viewpoint ${ }^{1,5}$. Asymptomatic adjacent segment degeneration [ASD] has also been considered to be a harbinger of symptomatic adjacent segment disease [ASDis]. In a meta-analysis, Zhang et al quoted a pooled annual incidence of $5.9 \%$ for ASD and $1.8 \%$ for $\overline{A S D i s}^{5}$.

Numerous parameters ranging from age, seg mental lumbar lordosis, global lumbar lordosis, pre-existing adjacent segment degeneration, preoperative bone mass densitom etry, body mass index [BMI], radiological sagittal para meters, osteoporosis, length of fusion and extension of fusion to sacrum have been incriminated as predisposing factors for ASD as well as ASDis ${ }^{1,5}$. Although these aspects have been studied extensively, the authors are not aware of any study pertaining to this problem in the Indian population. Hence, the present study was carried out to study incidence and risk factors for ASD and to elucidate association between radiographic ASD and clinical outcome.

\section{MATERIALS AND METHODS}

A retrospective study was conducted at a tertiary care referral center for spine surgery between September 2012 to October 2013 after appropria te IRB approval. Inclusion criteria were patients who underwent lumbar spinal fusion for spinal instability due to varied etiology: degenerative, spinal trauma, infection and deformity. Exclusion criteria were patients with postoperative iatrogenic surgical site infections, previous multiple surgeries, postoperative implant failure or pseudarthrosis and functional overlay.

All patients were operated by a single spine surgeon [YKP]. All patients were operated in the prone position with a standard midline open surgical approach. Care was taken not to violate the facet joint while inserting the cranial pedicle screw. However, the supraspinous attachment between the cranial instrumented vertebra with the immediate cranial vertebra was not retained in any of the patients. No surgical decompression was done at the cranial unfused segment. All patients were treated with posterolateral fusion with additional posterior fusion in areas where laminectomy was not found necessary. Titanium pedicle screws and rods were used in all patients.

Radiographs were done maintaining a uniform distance of 6 feet between the source and the subject. These were taken before surgery, in immediate postoperative period as well as at last follow-up. Additional flexion and extension radiographs in the lateral plane were procured at last followup. Global lumbar lordosis from Ll-Sl was noted in all radiographs in the standing position, with feet approximated and ensuring that hips and knees were straight, with fists clenched and kept on opposite clavicles. Additionally, angulation and translation of spinal motion segments immediately adjacent to fused spinal segment on the cranial and caudal aspect were studied on dynamic radiographs.

White and Panjabi's criteria [Table 1] were used to define radiographic $\mathrm{ASD}^{6}$.

Table 1: White And Panjabi's Criteria For Lumbar Spinal Instability On Dynamic Radiographs

\begin{tabular}{|l|l|l|l|}
\hline \multirow{4}{*}{$\begin{array}{c}\text { Adjacent segment } \begin{array}{c}\text { degen-eration } \\
\text { [ASD] is diagnosed } \\
\text { if }\end{array} \\
\begin{array}{c}\text { if } \\
\text { disc space }\end{array}\end{array}$} & $\begin{array}{l}\text { Inter-vertebral } \\
\text { dis-L2 }\end{array}$ & $\begin{array}{l}\text { Angu- } \\
\text { lation }\end{array}$ & Trans-lation \\
\cline { 2 - 4 } & L2-L3 & $>150$ & $>4.5 \mathrm{~mm}$ \\
\cline { 2 - 4 } & L3-L4 & $>150$ & $>4.5 \mathrm{~mm}$ \\
\cline { 2 - 4 } & L4-L5 & $>150$ & $>4.5 \mathrm{~mm}$ \\
\cline { 2 - 4 } & L5-Sl & $>200$ & $>4.5 \mathrm{~mm}$ \\
\hline
\end{tabular}


Visual Analogue Scale [VAS] was used for clinical assessments at final follow up. A $10 \mathrm{~mm}$ VAS was used to evaluate outcome. Unbearable pain intensity was recorded as 10 , and 0 indicated no pain at all. Scores were done independently for lower back as well as for radicular pain going down into the gluteal region or beyond. Walking distance at last follow-up was assessed for functional outcome ${ }^{7}$. Difference in ASD based on age of the patient at the time of surgery was assessed by grouping into those above and below 50 years of age.

Statistical analysis was done with the help of computer using Epidemiological Information Package [EPI 2010] developed by Centre for Degeneration Control, Atlanta. Chi square test was used to test the significance of difference between quantitative variables while Yate's and Fisher's chi square tests were used for qualitative variables. A two-tailed ' $p$ ' value less than 0.05 was considered to denote significant relationship.

\section{RESULTS}

Forty-two patients underwent lumbar fusion surgeries in the period mentioned above. Of these, twenty patients [48\%] were available for study after a minimum five years following surgery. Mean age was $49.4 \pm 17.4$ years. There were six males [30\%] and 14 females [70\%]. Follow-up duration was 72.6+9.8 months with a minimum of 60 months and maximum of 99 months. There were sixteen patients with degenerative spondylolistheses, two patients with degenerative scoliosis, one patient with tuberculosis and one with trauma. VAS Score for lower back at last follow up was $2.4 \pm 1.6$ [range: $0-5$ ] while it was $0.3 \pm 1.3$ [range: 0-4] for radicular pain. Walking distance at last follow up was $1.45 \pm 1.02$ kilometers [range: 0.5-4 kilometers].

Radiological ASD, as per the criteria elaborated in Table 1 was seen in 13 [65\%] out of 20 patients. Between angulation and translation, it was noted that the adjacent segments demonstrated instability only in the form of excessive angulation [Fig 1].

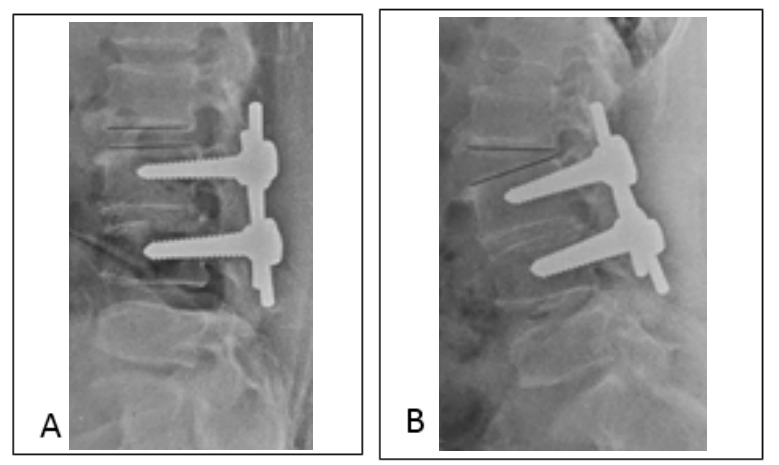

Figure 1: Radiographs Of $\bar{A}$ Patient Demonstrating Asd In The Form Of Angular Movement At L2-3 Level Exceeding 15 . A: Lateral Radiograph In Full Flexion At Five-years Followup. B: Lateral Radiograph In Full Extension At Five-years Follow-up

Eleven out of thirteen patients aged above 50 years at the time of surgery had adjacent segment degeneration whereas two out of seven patients below 50 years of age at the time of surgery had adjacent segment degeneration. This was found to be a statistically significant difference $[p=0.0223]$.

Ten patients had global lumbar lordosis less than $40^{\circ}$ in the immediate postoperative period. Nine out of these ten patients had ASD as compared to only four out of the other group with global lumbar lordosis more than $40^{\circ}$. This difference was statistically significant $[\mathrm{p}=0.0286]$.

Four out of six male patients and nine out of fourteen female patients had ASD. This difference was not statistically significant $[p=0.6641]$. Mean VAS score for back pain in patients with ASD was $2.23 \pm 1.64$ whereas it was $2.71 \pm 1.5$ in those without ASD. This difference was not statistically significant $[p=0.4906]$. Mean VAS score for radiculopathy in patients with ASD was $0.46+1.2$ whereas it was zero in all those without ASD. This difference too, was not statistically significant $[p=0.287]$.

Seven patients had extension of fusion till sacrum while thirteen had at least one motion segment spared caudally. Six out of the former and seven out of the latter group had radiological ASD. This difference too, was statistically insignificant $[p=0.3916]$.

Twelve out of sixteen patients with fusion upto three motion segments had ASD. On the other hand, one out of four patients with fusion exceeding three motion segments had ASD. Analysis of this data did not reveal any significant correlation between length of fusion and development of $\mathrm{ASD}[\mathrm{p}=0.1531]$.

\section{DISCUSSION}

Data analysis has revealed a $276 \%$ increase in elective lumbar fusions in the US for degenerative conditions from 2002 to $2014^{8}$. Given this increase in the number of fusions, it would be essential to bear in mind the long-term consequences of this procedure in the form of ASD and ASDis.

Kumar MN et al noted that 38\% [31 of 83] patients had cranial ASD at an average of 5.2 years following lumbar fusion surgery ${ }^{9}$. Soh J et al also noted ASD in 38\% [21 of 55] patients at the end of minimum five years of follow-up ${ }^{10}$. Cheh $\mathrm{G}$ et al noted ASD in $42.6 \%$ [80 of 188] of patients at minimum fiveyear follow-up ${ }^{11}$. At the end of a mean follow-up of 4.6 years, Hikata et al noted ASD in $57.4 \%$ [31 of 54] patients ${ }^{12}$. In a comparative study over a mean follow-up of 3.7 years between lumbar fusion surgery through anterior versus posterior approach, Min JH et al noted ASD in 82.6\% [19 of 23] patients who underwent fusion through posterior approach ${ }^{13}$. After $a$ minimum follow-up of five years, $\mathrm{Kim} \mathrm{KH}$ et al noted ASD in $72.7 \%$ [33 of 44] patients with isthmic spondylolisthesis and in $84 \%$ [22 of 25] patients with degenerative spondylolisthesis ${ }^{14}$.

The present study was carried out to ascertain data related to radiological ASD, based on dynamic flexion-extension radiographs following lumbar fusion surgery in the Indian scenario. Patients were studied over a minimum follow-up period of five years. Assessment of ASD and its correlation to various parameters were studied. Our study revealed ASD in thirteen [65\%] out of twenty patients. Between abnormal angulation and translation, patients demonstrated ASD primarily in the form of abnormal angulation in the present cohort.

There can be various reasons for such widely varying incidence of ASD in literature. One of the likely reasons is variation in parameters used to define ASD. Sakaura $\mathrm{H}$ et al considered translation more than three millimeters along with posterior opening of more than $5^{\circ}$ as criteria for $\mathrm{ASD}^{15}$. Chen BL et al defined ASD on the basis of dynamic angulation $>5^{\circ}$ and anteroposterior translation more than three millimeters ${ }^{16}$. In a study of 73 patients over fifteen years, Maruenda JI et al considered dynamic angulation greater than ten degrees and anteroposterior translation more than three millimeters as indicators of $\mathrm{ASD}^{17}$. However, physiological angular motion is not uniform across all the lumbar motion segments ${ }^{6}$. Hence, we felt it more appropriate to apply the radiological instability criteria of White and Panjabi in our study ${ }^{6}$.

It may be argued that ASD incidence was relatively on the higher side in our study because of sacrifice of supraspinous ligament at the cranial adjacent level. In fact, Lai PL et al 
suggested that removal of supraspinous ligament at the cranial adjacent level can indeed spike the incidence of $\mathrm{ASD}^{18}$. However, $\mathrm{Yu} \mathrm{CH}$ et al carried out a study to identify difference in ASD development between patients who had undergone complete laminectomy with sacrifice of supraspinous ligament at the cranial adjacent level versus those in whom a partial laminectomy was done with retention of this ligament ${ }^{19}$. These authors could not identify any difference in the incidence of ASD between the two groups.

In a study of 131 people, Maragkos GA et al noted that there was a lower incidence of ASD in older people ${ }^{20}$. However, this finding was contradicted in another study of 188 patients by Cheh $\mathrm{G}$ et al who found out a higher risk of development of ASD in patients than 50 years ${ }^{11}$. Aota et al and Rahm et al too, regarded patient's age as a major risk factor for development of $\mathrm{ASD}^{21,22}$. In our study too, we noted similar findings of higher incidence of ASD in patients over the age of 50 years.

Etebar and Cahill suggested that the rate of degeneration at adjacent segments was higher in females after menopause ${ }^{23}$. However, Kumar MN et al and Anandjiwala J et al showed no significant influence of gender on ASD in their studies ${ }^{9,24}$. Our study too, could not identify any difference in the incidence of ASD between males and females.

Cheh $\mathrm{G}$ et al as well as Masevnin S et al noted that length of fusion, particularly beyond three lumbar motion segments was a significant risk factor in the development of $\mathrm{ASD}^{11,25}$. However, Penta $\mathrm{M}$ et al performed a radiologic study using plain films and MRI in 52 patients to evaluate relationship between adjacent level disease and fusion length ${ }^{26}$. At tenyear follow-up, the authors found that $32 \%$ of these 52 patients had degenerative changes and that this percentage was not influenced by length of fusion. Wiltse LL et al too, found that length of fusion was not significant in the development of $\mathrm{ASD}^{27}$. Ghiselli et al too, came up with similar findings in their study $^{28}$. In our study too, we found no significant relationship between adjacent segment degeneration and length of fusion.

In an analysis of 511 patients, Bydon $\mathrm{M}$ et al noted that patients who had floating fusion [leaving L5-Sl segment unfused] had a higher likelihood to develop ASD as compared to those with fusion extending upto sacrum ${ }^{29}$. Similar opinion was expressed by Disch AC et al as well ${ }^{30}$. However, Liao JC_et al conducted a study on 107 patients with degenerative spondylolisthesis at L4-5 level ${ }^{31}$. These patients had preexisting asymptomatic L5-S1 disc degeneration. The authors, however, could not find any advantage in extending fusion to $\mathrm{Sl}$ as compared to performing floating fusion ${ }^{31}$. Similar views of avoiding L5-Sl fusion for the sake of minimizing ASD were expressed by Miyakoshi $\mathrm{N}$ et al as well by Ghiselli $\mathrm{G}$ et al as well ${ }^{32,33}$. In current study too, we found no significant relationship between incidence of ASD and fusion done upto sacrum versus lumbar floating fusion.

Lai PL et al noted no correlation between lumbar lordosis and development of $\mathrm{ASD}^{34}$. Liao JC et al and Chen BL et al too, could not identify any correlation between these two parameters ${ }^{16,31}$. However, Umehara $S$ et al reported a human cadaveric study in which they noted increased posterior element stress at the adjacent levels in patients with instrumentation with loss of lordosis ${ }^{35}$. Bagheri SR et al carried out a retrospective study on 630 patients and noted that patients with ASD had a significantly lower postoperative global lumbar lordosis as compared to the other ${ }^{36}$. In our study too, it was noted that ASD was more common in patients with global lumbar lordosis [Ll-S1] less than $40^{\circ}$.

It is intuitive logic to expect radiological ASD to lead to some form of clinical symptoms ${ }^{37}$. Yang JY et al noted significant correlation between ASD and clinical outcomes ${ }^{37}$. However, $a$ study of 98 patients by Ha KY et al led them to conclude that there is no correlation between ASD and clinical outcome ${ }^{38}$. Our study too, could not identify any correlation between radiological ASD and clinical parameters in terms of VAS scores for lower back or lower limbs nor with the walking capacity of patients at last follow-up.

The present study, however, has its limitations. The study population has diverse etiology. However, ASD as a phenomenon is being studied to note the effects of fusion on segment adjacent to fusion. In view of this, the authors feel that the same may not be of relevance since fusion as a surgical method was the same in all cases. While patient-reported outcome scores are ideal, we do not have validated outcome scores in local Indian languages making it difficult for patients to fill up these of their own ${ }^{39}$. Being a retrospective study, full length standing radiographs were not routinely ordered for all patients. Hence, we could not analyze radiological sagittal parameters such as pelvic tilt and sagittal vertical axis nor could we analyze other parameters such as segmental lordosis over the fused segment or spinal stenosis and disc degeneration on MRI. Also, the sample size is small. However, the present study can certainly provide the springboard for further studies in this direction in the Indian population.

\section{CONCLUSIONS}

To conclude, radiological ASD is a fairly common phenom enon following lumbar spinal fusion in the long term. It is more commonly observed in patients aged more than 50 years at the time of surgery. It is also more commonly observed in patients in whom the immediate postoperative global lumbar lordosis [Ll-Sl] was less than $40^{\circ}$. However, the present study could not identify any correlation of ASD to other factors such as gender, length of fusion and extension of fusion till sacrum.

\section{REFERENCES}

1. Trivedi NN, Wilson SM, Puchi LA, Lebl DR. Evidence-Based Analysis of Adjacent Segment Degeneration and Disease After LIF: A Narrative Review. Global Spine J. 2018 Feb;8(1):95-102

2. Pellisé F, Hernández A, Vidal X, Minguell J, Martínez C, Villanueva C. Radiologic assessment of all unfused lumbar segments 7.5 years after instrumented posterior spinal fusion. Spine (Phila Pa 1976). 2007 Mar 1;32(5):574-9

3. Bydon M, Macki M, Kerezoudis P, Sciubba DM, Wolinsky JP, Witham TF, Gokaslan ZL, Bydon A. The incidence of adjacent segment disease after lumbar discectomy: A study of 751 patients. J Clin Neurosci. 2017 Jan;35:42-46

4. Bastian L, Lange U, Knop C, Tusch G, Blauth M. Evaluation of the mobility of adjacent segments after posterior thoracolumbar fixation: a biomechanical study. Eur Spine J. 2001 Aug; 10(4):295-300

5. Zhang C, Berven SH, Fortin M, Weber MH. Adjacent Segment Degeneration Versus Disease After Lumbar Spine Fusion for Degenerative Pathology: A Systematic Review With Meta-Analysis of the Literature. Clin Spine Surg. 2016 Feb;29(1):21-9

6. White AA, Punjabi MM. Clinical biomechanics of the spine 2nd ed. Philadelphia: Lippincott Williams \& Wilkins ; 1990

7. Bouras T, Zairi F, Loufardaki M, Triffaux M, Stranjalis G. Which functional outcome parameters correlate better with elderly patients' satisfaction after non-fusion lumbar spine surgery? J Neurosurg Sci. 2019 Aug;63[4]:365-371

8. Deng H, Yue JK, Ordaz A, Suen CG, C Sing D. Elective lumbar fusion in the United States: national trends in inpatient complications and cost from 20022014. J Neurosurg Sci. 2019 Apr 2

9. Kumar MN, Baklanov A, Chopin D. Correlation between sagittal plane changes and adjacent segment degeneration following lumbar spine fusion. Eur Spine J. 2001 Aug; 10(4):314-9

10. Soh J, Lee JC, Shin BJ. Analysis of risk factors for adjacent segment degeneration occurring more than 5 years after fusion with pedicle screw fixation for degenerative lumbar spine. Asian Spine J. 2013 Dec;7(4):273-81

11. Cheh G, Bridwell KH, Lenke LG, Buchowski JM, Daubs MD, Kim Y, Baldus C. Adjacent segment disease followinglumbar/thoracolumbar fusion with pedicle screw instrumentation: a minimum 5-year follow-up. Spine (Phila Pa 1976). 2007 Sep 15;32(20):2253-7

12. Hikata T, Kamata M, Furukawa M. Risk factors for adjacent segment disease after posterior lumbar interbody fusion and efficacy of simultaneous decompression surgery for symptomatic adjacent segment disease. J Spinal Disord Tech. 2014 Apr;27(2):70-5

13. Min JH, Jang JS, Lee SH. Comparison of anterior- and posterior-approach instrumented lumbar interbody fusion for spondylolisthesis. J Neurosurg Spine. 2007 Jul; 7(1):21-6

14. Kim KH, Lee SH, Shim CS, Lee DY, Park HS, Pan WJ, Lee HY. Adjacent segment disease after interbody fusion and pedicle screw fixations for isolated L4-L5 spondylolisthesis: a minimum five-year follow-up. Spine (Phila Pa 1976). 2010 Mar 15;35(6):625-34

15. Sakaura H, Ikegami D, Fujimori T, Sugiura T, Mukai Y, Hosono N, Fuji T. Early cephalad adjacent segment degeneration after posterior lumbar interbody 
fusion: a comparative study between cortical bone trajectory screw fixation and traditional trajectory screw fixation. J Neurosurg Spine. 2019 Oct 18:32(2):155-159

16. Chen BL, Wei FX, Ueyama K, Xie DH, Sannohe A, Liu SY. Adjacent segment degeneration after single-segment PLIF: the risk factor for degeneration and its impact on clinical outcomes. Eur Spine J. 2011 Nov;20(11):1946-50

17. Maruenda JI, Barrios C, Garibo F, Maruenda B. Adjacent segment degeneration and revision surgery after circumferential lumbar fusion: outcomes throughout 15 years of follow-up. Eur Spine J. 2016 May;25(5):15501557

18. Lai PL, Chen LH, Niu CC, Fu TS, Chen WJ. Relation between laminectomy and development of adjacent segment instability after lumbar fusion with pedicle fixation. Spine (Phila Pa 1976) 2004;29:2527-32

19. Yu CH, Lee JE, Yang JJ, Chang BS, Lee CK. Adjacent Segment Degeneration after Single-Level PLIF: Comparison between Spondylolytic Spondylolisthesis, Degenerative Spondylolisthesis and Spinal Stenosis. Asian Spine J. 2011 Jun; 5(2):82-90

20. Maragkos GA, Atesok K, Papavassiliou E. Prognostic Factors for Adjacent Segment Disease After L4-L5 Lumbar Fusion. Neurosurgery. 2019 Jun 27. pii: nyz241

21. Aota Y, Kumano K, Hirabayashi S. Postfusion instability at the adjacent segments after rigid pedicle screw fixation for degenerative lumbar spinal disorders. J Spinal Disord. 1995 Dec;8(6):464-73

22. Rahm MD, Hall BB. Adjacent-segment degeneration after lumbar fusion with instrumentation: a retrospective study. J Spinal Disord. 1996 Oct;9(5):392-400

23. Etebar S, Cahill DW. Risk factors for adjacent-segment failure following lumbar fixation with rigid instrumentation for degenerative instability. J Neurosurg. 1999 Apr;90(2 Suppl):163-9

24. Anandjiwala J, Seo JY, Ha KY, Oh IS, Shin DC. Adjacent segment degeneration after instrumented posterolateral lumbar fusion: a prospective cohort study with a minimum five-year follow-up. Eur Spine J. 2011 Nov;20(11):1951-60

25. Masevnin S, Ptashnikov D, Michaylov D, Meng H, Smekalenkov O, Zaborovskii N. Risk factors for adjacent segment disease development after lumbar fusion. Asian Spine J. 2015 Apr;9(2):239-44

26. Penta M, Sandhu A, Fraser RD. Magnetic resonance imaging assessment of disc degeneration 10 years after anterior lumbar interbody fusion. Spine. 1995 Mar 15;20[6]:743-7.

27. Wiltse LL, Radecki SE, Biel HM, DiMartino PP Oas RA, Farjalla G et al. Comparative study of the incidence and severity of degenerative change in the transition zones after instrumented versus noninstrumented fusions of the lumbar spine. J Spinal Disord. 1999 Feb; 12[1]:27-33.

28. Ghiselli G, Wang JC, Bhatia NN, Hsu WK, Dawson EG. Adjacent segment degeneration in the lumbar spine. J Bone Joint Surg Am. 2004 Jul;86-A[7]:1497503.

29. Bydon M, Xu R, Santiago-Dieppa D, Macki M, Sciubba DM, Wolinsky JP, Bydon A, Gokaslan ZL, Witham TF. Adjacent-segment disease in 511 cases of posterolateral instrumented lumbar arthrodesis: floating fusion versus distal construct including the sacrum. J Neurosurg Spine. 2014 Apr;20(4):380-6

30. Disch AC, Schmoelz W, Matziolis G, Schneider SV, Knop C, Putzier M. Higher risk of adjacent segment degeneration after floating fusions: long-term outcome after low lumbar spine fusions. J Spinal Disord Tech. 2008 Apr;21(2):79-85

31. Liao JC, Chen WJ, Chen LH, Niu CC, Keorochana G. Surgical outcomes of degenerative spondylolisthesis with L5-Sl disc degeneration: comparison between lumbar floating fusion and lumbosacral fusion at a minimum 5-year follow-up. Spine.2011 Sep 1;36[19]:1600-7

32. Miyakoshi N, Abe E, Shimada Y, Okuyama K, Suzuki T, Sato K. Outcome of one-level posterior lumbar interbody fusion for spondylolisthesis and postoperative intervertebral disc degeneration adjacent to the fusion. Spine [Phila Pa 1976] 2000:25:1837-1842.

33. Ghiselli G, Wang JC, Hsu WK, Dawson EG. L5-S1 segment survivorship and clinical outcome analysis after L4-L5 isolated fusion. Spine. 2003 Jun 15;28[12]:1275-80.

34. Lai PL, Chen LH, Niu CC, Chen WJ. Effect of postoperative lumbar sagittal alignment on the development of adjacent instability. J Spinal Disord Tech. 2004 Oct; 17(5):353-7

35. Umehara S, Zindrick MR, Patwardhan AG, Havey RM, Vrbos LA, Knight GW, Miyano S, Kirincic M, Kaneda K, Lorenz MA. The biomechanical effect of postoperative hypolordosis in instrumented lumbar fusion on instrumented and adjacent spinal segments. Spine (Phila Pa 1976). 2000 Jul 1;25(13):161724

36. Bagheri SR, Alimohammadi E, Zamani Froushani A, Abdi A. Adjacent segment disease after posterior lumbar instrumentation surgery for degenerative disease: Incidence and risk factors. J Orthop Surg (Hong Kong). 2019 May-Aug;27(2):1-6

37. Yang JY, Lee JK, Song HS. The impact of adjacent segment degeneration on the clinical outcome after lumbar spinal fusion. Spine (Phila Pa 1976). 2008 Mar 1;33(5):503-7

38. Ha KY, Son JM, Im JH, Oh IS. Risk factors for adjacent segment degeneration after surgical correction of degenerative lumbar scoliosis. Indian J Orthop. 2013 Jul:47(4):346-51

39. Beaton DE, Bombardier C, Guillemin F, Ferraz MB. Guidelines for the process of cross-cultural adaptation of self-report measures. Spine (Phila Pa 1976). 2000;25(24):3186-3191. 